\title{
INNOVATIVE PROJECT FOR ROMANIANS HEALTH PROBLEMS. THE LIFESTYLE CENTER FOR HEALTH
}

\author{
Marinel Cornelius Dinu ${ }^{330}$ \\ Eugen Cornel Mihai ${ }^{331}$
}

https://doi.org/10.31410/itema.2018.965

\begin{abstract}
At present, in the context of the development of society, this great world is sick, and wherever the children of the people live, the mistaken customs and suffering abound. Despite the progress of medical and surgical science; in spite of the army of the great skilled physicians who, like a white army, are thrown into the fight against disease and death, in all civilized countries, suffering and illness grow rapidly. We mingled in the good course of the wonderful human machining, and its delicate mechanism was made to work against the law of its life and resistance; the consequences were sickness and death. What is the remedy? Above all, it is knowledge. What are the laws of our being, both spiritual and physical?

It is the mission of that Center to completely rebuild the people; His bringing to life project came from discovering the needs of men to give them health, peace and completeness of character. How to preserve and improve health, how to prevent and treat disease is the goals of this Center.

The perfect remedy for the sick of mankind is to guard and cherish all the spiritual, mental and physical laws of our being. Teachings are not purely technical. They can also be understood by non-specialists. The exposed requirements regarding spiritual, mental and physical health and well-being are so logical that they can be fulfilled. Of particular value is what is related to disease prevention; for, as an old proverb says, it is better for a foresight than for abundant treatment.

Clarifying prevention requires immediate intervention in Romania, but also in other countries of the world. This document clarifies the most important aspect of prevention, lifestyle and education.
\end{abstract}

Keywords: health, education, prevention, lifestyle, well-being.

\section{INTRODUCTION}

$\mathrm{I}$ ndividuals and legal persons have the right to establish medical and sanitary institutions (curative, prophylactic, pharmaceutical and other) and are responsible for their financial and technical-material insurance, for the organization of healthcare and for their quality, according to the legislation in force. And we will refer specifically to Preventive Medicine Centers and Preventive Medicine Hospitals in the Western countries and then to Romania (Herghelia-Tg Mureş, Podiş-Bacău, Codlea- Braşov- building, Malul Mierii- Dâmboviţa).

These centers have started on a health education basis as the author says: Healthy lifestyle practices are planned for people to be determined to adhere to the principles of an optimal lifestyle (Pakholok O., 2013).

\footnotetext{
${ }^{330}$ Bucharest University of Economic Studies, Romania

${ }^{331}$ Polytechnic University of Bucharest; Romania
} 
The purpose of this study is to present the principle according to which all state or public organizations and citizens are obliged to respect, in their work, the law on health. One of the principles of the health care system is also that of accountability for each person's health. The method used is to promote health education through health promotion programs through health education for the population.

\section{CONTEXT}

The impact of health education in such preventive medicine centers will somewhat influence the health of the population. Education, age and occupation are very important in conforming to health through education. Empowering the population for health involves identifying a better health program. Through population accountability programs, change can be promoted in order to adopt a healthy lifestyle.

The results of December 2014 showed that, from the body mass index point of view Romania was among the countries with a fairly high percentage of overweight, but obesity was lower than other European countries (Figure 1).

One of the findings of the study was that countries that had higher spending on health have a better state of health for the inhabitants, and a healthier lifestyle leads to increased life expectancy.

Figure 1: Overweight in all countries

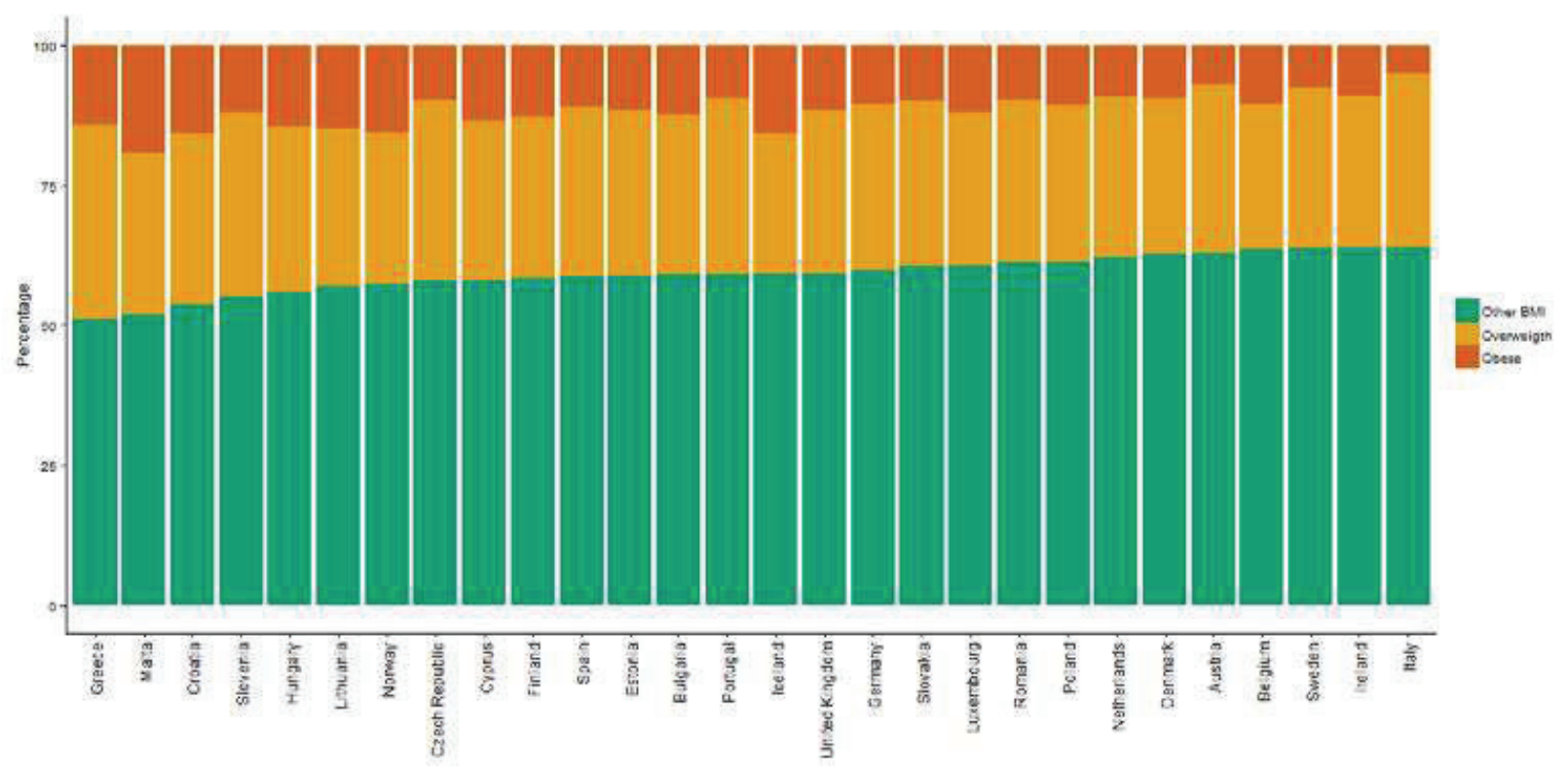

Source: Final report Maceli

This can be a real support in the process of changing and gaining health. Generally, the main factors influencing lifestyle are dietary trends, physical exercise, even unhealthy habits; As well as working conditions, public and domestic behaviors. In order to channel resources for better health, health clubs, sports halls, fitness centers have been set up so that people can invest in their health. 


\section{CIRCUMSTANCES}

In order to identify the fulfillment of the task of accountability of the population to health, we will have indicators that show how effective the strategic objectives of health education were. To strengthen the goals, healthy lifestyles will be promoted through various products and services so that people can be attracted to invest in health. Individuals are affected by stress and a sedentary lifestyle, rated as "modern diseases". The impact of obesity on the population will in some cases influence the health of citizens.

Obese children and adolescents have an increased risk of joint problems, sleep apnea, social, psychological problems. The obese child has a high risk of becoming obese adult. That is why it needs to intervene early, preventing health complications. A UNICEF 2009-2010 report that looked at 11, 13 and 15-year-old children in 29 countries showed that the highest percentage of obese children was registered in the US (nearly $30 \%$ ), our country being (15\%) (Figure 2). The percentage of children who ate daily breakfast (considered the main meal of the day) was the highest in the Netherlands (almost 90\%), Romania being in the last place (about 45\%) (Figure $3)$.

Figure 2: Percentage of overweight children

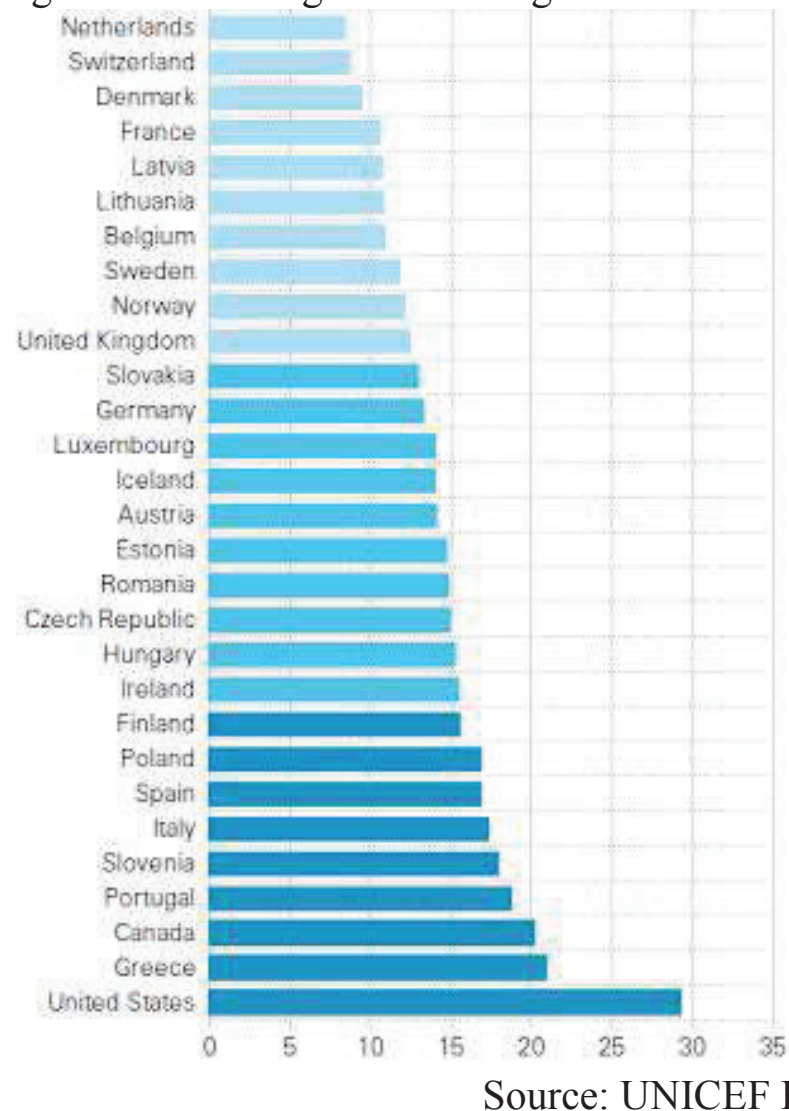

Figure 3: Breakfast consumption every day

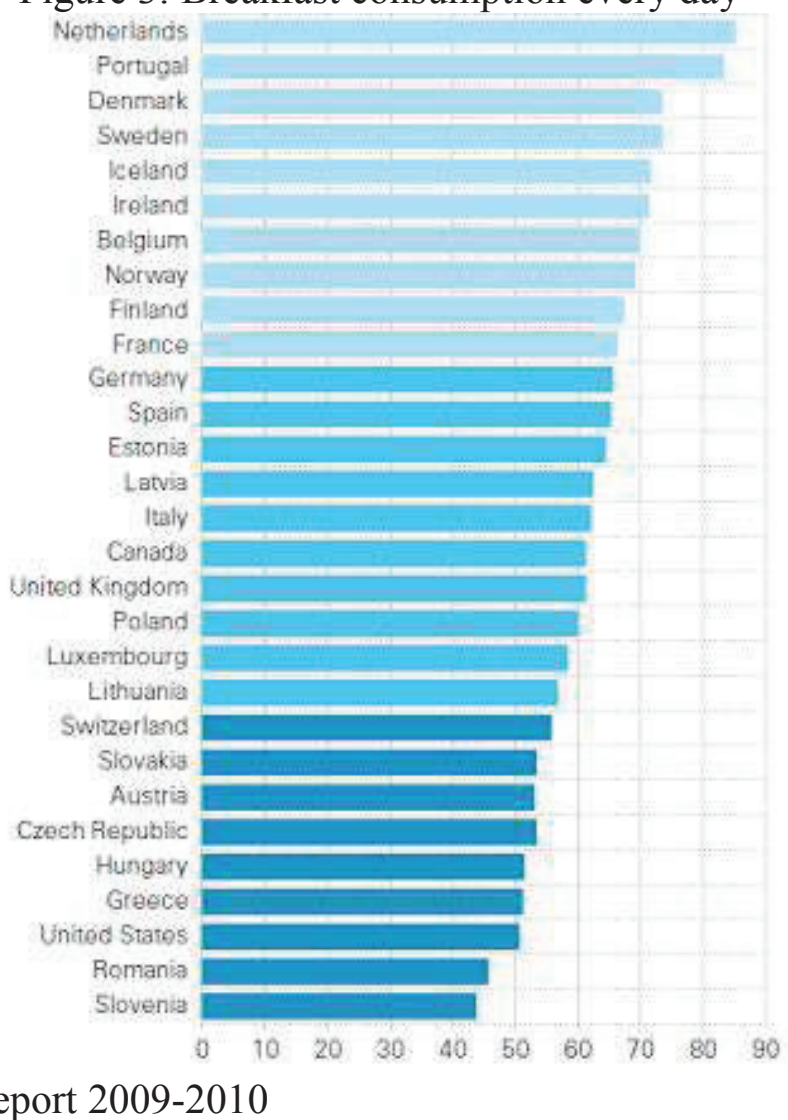

There is more and more the category of people who could have correctly lifestyle, and have a balanced diet so that they are not affected by these "diseases" even outside the city. There are several different types of stress. It is generally accepted that accumulated stress can fuel health problems and food can help or hinder the process, inevitably involving many people. Education, age, occupation are of great importance. These include sedentary work, balanced nutrition and exercise time. We know that balanced nutrition is not the best way to have optimal health. But 
diet can relieve disease symptoms, and a program to promote an ideal diet, as well as preventative medicine, would support the move to a change in gaining health.

\section{CONCLUSIONS}

For people to become more responsible for health, strategies must be found so that lifestyle change can be a good outcome for health education. By going through different stages of change, day after day, new good habits can be adopted so that people can acquire practical solutions to combat bad habits that affect health. To gain success from health education, it takes an impact of change that develops a process of adopting a new lifestyle. To start a change program, a target and goals are needed over a determined period. A monthly analysis of the change process reports can highlight the pluses and minuses of the Health Empowerment Program and the adjustment and adoption of new education strategies.

It is the mission of the Malul Mierii Center to completely rebuild the people; His bringing to life project came from discovering the needs of men to give them health, peace and completeness of character. How to preserve and improve health, how to prevent and treat disease is the goals of this Center.

\section{REFERENCES}

[1] Gulap M. (2013) Study on the Importance of Physical Education in Fighting Stress and a Sedentary Lifestyle, Elsevier Ltd

[2] Groven KS. (2013) Weight loss surgery as a tool for changing lifestyle? Med Health Care and Philos, Springer Science+Business Media Dordrecht 16: 699-708.

[3] Pakholok O. (2013) The Idea of Healthy Lifestyle and Its Transformation Into HealthOriented Lifestyle in Contemporary Society. Sage Open.

[4] Popescu-Neveanu P. (1979) Dicționar de psihologie, București: Albatros.

[5] Reunen T. (2015) Human Factor in Time Management. Elsevier Ltd.

[6] Pakholok O. (2013) The Idea of Healthy Lifestyle and Its Transformation Into HealthOriented Lifestyle in Contemporary Society. Sage Open, Vol. 1(10), pp: 2.

[7] Reunen T. (2015) Human Factor in Time Management. Elsevier Ltd.

[8] Robinson N. (2014) Driving social impact with common global indicators for healthy lifestyle programs: Lessons learned. Food and Nutrition Bulletin 35: S 164.

[9] Campbell , T Colin (2006) The China Study, Dallas: BenBella Books, Inc. 13. 